\title{
Atributos físicos e biológicos em Vertissolo Cromado sob agricultura biodinâmica na mesorregião do sertão Paraibano ${ }^{1}$
}

\author{
Gysleynne Gomes da Silva Costa ${ }^{2}$, Adriana Ferreira Martins ${ }^{3}$, Flávio Pereira de Oliveira ${ }^{4}$
}

\begin{abstract}
Resumo: Alterações no solo são capazes de modificar seu funcionamento natural, tornando o acompanhamento de impactos de diferentes tipos de uso sempre necessário. O presente artigo teve como objetivo avaliar atributos físicos e biológicos em Vertissolo sob agricultura biodinâmica na mesorregião do sertão Paraibano, especificamente nas Várzeas de Sousa (PB). A coleta das amostras foram realizadas em Vertissolo Cromado sob diferentes condições de usos em duas profundidades de amostragem. Nos atributos biológicos foram analisados diversidade, equitabilidade e atividade microbiana e macrofauna edáfica, enquanto nos físicos, análise textural, densidade do solo, macro e microporosidade, porosidade total e retenção de água no solo. Observou-se que na parte biológica a diversidade microbiana total se mostrou maior na área sob vegetação nativa, independente da condição de uso e profundidade. A atividade microbiana foi mais elevada na área sob capim tifton, assim como obteve maior densidade de indivíduos da macrofauna, tendo como ordem de destaque, Hymenoptera. Porém, índices de diversidade mostraram menor diversidade e equitabilidade na mesma, provavelmente pela dominância deste grupo. Em relação aos atributos físicos, observou-se baixa capacidade de retenção de água, independente dos usos e profundidades de amostragem, enquanto a densidade média apresentou mais elevada na camada subsuperficial.
\end{abstract}

Palavras-chave: Microrganismos; Estrutura do solo; Manejo.

\section{Physical and biological attributes in Chromic Vertisol under biodynamic agriculture in the mesoregion of the Paraíba hinterland}

\begin{abstract}
Changes are not only capable of modifying their natural functioning, making tracking of impacts of different types of use always necessary. The present article had as objective to evaluate physical and biological attributes in Vertisol under biodynamic agriculture in the mesoregion of the Paraíba hinterland, specifically in the. The samples were collected in Chromic Vertisol under different conditions of use at two sampling depths. In the biological attributes were analyzed diversity, equitability and microbial activity and edaphic macrofauna, while in the physical, textural analysis, soil density, macro and microporosity, total porosity and water retention in the soil. It was observed that in the biological part the total microbial diversity showed to be greater in the area under native vegetation, independent of the condition of use and depth. Microbial activity was higher in the area under tifton grass, as well as higher density of macrofauna individuals, with Hymenoptera being the most prominent order. However, diversity indexes showed less diversity and equitability in the same, probably due to the dominance of this group. Regarding the physical attributes, a low water retention capacity was observed, regardless of the uses and depth of sampling, while the average density was higher in the subsurface layer.
\end{abstract}

Keywords: Microorganisms; Soil structure; Management.

${ }^{1}$ Submetido em 23/03/2017 e aprovado em 02/02/2018

${ }^{2}$ Biológa; Universidade Federal da Paraíba (UFPB), Centro de Ciências Agrárias, Areia-PB, CEP: 58397-000; E-mail: gysg.costa@ gmail.com ${ }^{3}$ Doutora em Ciência do Solo; Bolsista PNPD, Universidade Federal da Paraíba (UFPB), Centro de Ciências Agrária, Programa de Pósgraduação em Ciência do Solo, Areia-PB, CEP: 58397-000; E-mail: biol.adriana@ gmail.com

${ }^{4}$ Doutor em Ciência do Solo; Professor Adjunto, Universidade Federal da Paraíba (UFPB), Centro de Ciências Agrárias, Departamento de Solos e Engenharia Rural, Areia-PB, CEP: 58397-000; E-mail: pereira@cca.ufpb.br 


\section{Introdução}

Os solos guardam uma abundante biodiversidade, assim como diferentes condições abióticas que interagem entre si. Basicamente a parte viva do solo encontra-se constituída de pequenos animais e microrganismos (Abdulkadir e Waliyu, 2012). Estes microrganismos presentes no solo atuam em importantes processos ambientais, como na decomposição da matéria orgânica estando, portanto, relacionados aos ciclos biogeoquímicos. Pequenos invertebrados também participam de importantes processos no solo, tais como, decomposição, ao realizarem rearranjo de detritos e sua desintegração (Souto et al., 2008). Fatores abióticos, como os atributos físicos, estão relacionados às atividades desses organismos edáficos interagindo, afetando e sendo afetados por essas atividades.

Sendo assim, o solo é um ambiente estruturalmente definido. Mas, com a crescente demanda populacional da atualidade, o uso intensivo e desordenado do solo vem ocasionando consideráveis desequilíbrios neste ambiente. Dentre as formas de manejo, a agricultura orgânica é um método, considerado sustentável, que vem sendo adotada, constituindo a Agricultura Biodinâmica uma vertente desta agricultura. Contudo, qualquer prática agricultável, mesmo as práticas agrícolas conservacionistas, pode afetar a biota em diferentes graus, tornando o monitoramento da qualidade do solo sempre importante (Rieff, 2010). Porém nestes tipos de práticas, manejos de cultivos diferentes podem diferenciar todas as estruturas bióticas e abióticas do solo.

Assim, estudos de indicadores biológicos e físicos, além de químicos, do solo no que se refere ao cultivo orgânico, são importantes para verificação da sustentabilidade deste tipo de manejo, reunindo parâmetros que podem nortear indicadores de qualidade do solo, auxiliando na avaliação da produtividade, monitoramento de mudanças ambientais e ainda, em iniciativas governamentais de políticas agrícolas (Lima et al., 2007).

Deste modo, o presente trabalho teve como objetivo avaliar atributos físicos e biológicos em Vertissolo Cromado sob agricultura biodinâmica na mesorregião do sertão Paraibano.

\section{Material e Métodos}

As amostras de solo foram coletadas na Fazenda Águas de Tamanduá, no Perímetro Irrigado Várzeas de Sousa, localizada no município de Sousa - Estado da Paraíba, mesorregião do Sertão Paraibano. A região possui características de precipitação média anual de $838,9 \mathrm{~mm}$, clima quente, semiárido, tropical nordeste oriental, com 7 a 8 meses secos (Santos, 2012). Seu bioma predominante é a Caatinga. $\mathrm{Na}$ área em estudo predomina Vertissolo Cromado (Embrapa, 2014). A referida fazenda foi implantada em 2008, praticando desde então agricultura e pecuária Biodinâmica, possuindo selo de certificação do Instituto Biodinâmico de Desenvolvimento Rural de Botucatu (IBD).

Foram coletadas amostras de solo nas áreas de cultivo de romã (Punicata granatum L.), capim tifton (Cynodon spp) e vegetação nativa. Para cada condição de uso foram coletadas 10 amostras deformadas e indeformadas, sendo cinco na camada de 0-10 $\mathrm{cm}$ e cinco na camada de $10-20 \mathrm{~cm}$ de profundidade, totalizando 30 amostras. As amostras, em cada uso do solo, foram coletadas em uma área representativa de 1 hectare. Posteriormente foram realizadas análises de atributos biológicos no Laboratório de Microbiologia, do Departamento de Ciências Biológicas, do Centro de Ciências Agrárias, da Universidade Federal da Paraíba. Enquanto que os atributos físicos foram analisados no Laboratório de Física do Solo, do Departamento de Solos e Engenharia Rural, da mesma instituição. A caracterização química do solo foi realizada no Laboratório de Química e Fertilidade do Solo, também pertencente ao Departamento de Solos e Engenharia Rural (Tabela 1).

\subsection{Caracterização de atributos biológicos}

A atividade microbiana foi medida pelo método de respiração basal (Vance et al., 1987; adaptado por Martins, 2015). Para avaliação da diversidade microbiana foi analisado o número de fungos e bactérias pela determinação por meio de unidades formadoras de colônias (UFC) utilizando-se o método de inoculação de suspensões diluídas de solos em meio de cultura BDA (Batata - Dextrose - Ágar), com três repetições por diluição para cada amostra de solo, de cada área e profundidade estudada. $\mathrm{Na}$ preparação do meio de cultura foi adicionado 1,0 $\mathrm{g}$ de antibiótico (sulfato de gentamicina), quando destinado à contagem do número de colônias de fungos e $1,0 \mathrm{~g}$ de fungicida (grupo químico

Revista Agropecuária Técnica, Areia-PB, v. 39, n. 1, p. 31-42, 2018

DOI: 10.25066/agrotec.v39i1.34463 
benzimidazol), quando destinado à contagem do número de colônias de bactérias.

Além da contagem de UFC, para bactérias foi realizado o teste de Gram, utilizando o conjunto para coloração de Gram Laborclin. Em relação aos fungos, utilizou-se o procedimento realizado de acordo com Martins (2015).

Tabela 1 Valores de atributos químicos (fertilidade) de Vertissolo Cromado sob diferentes condições de uso

\begin{tabular}{|c|c|c|c|c|c|c|c|c|c|c|c|c|c|c|}
\hline Área $^{1}$ & $\mathrm{pH}^{2}$ & $\mathrm{pH}^{3}$ & $\mathbf{P}$ & $\mathbf{K}^{+}$ & $\mathrm{Ca}^{+2}$ & $\mathrm{Mg}^{+2}$ & $\mathbf{A l}$ & $\mathrm{H}+\mathrm{Al}$ & $\mathrm{Na}^{+}$ & SB & CTC & $\mathbf{V}$ & $\mathbf{m}$ & MO \\
\hline & $(1: 2,5)$ & & $\mathrm{mg} \mathrm{kg}^{-1}$ & \multicolumn{8}{|c|}{$\begin{array}{c}\cdots-\cdots \\
\text { 0-10 }\end{array}$} & \multicolumn{2}{|c|}{--\%-- } & $\mathrm{g} \mathrm{kg}^{-1}$ \\
\hline CT & 7 & 5,9 & 37 & 19,9 & 233 & 86 & 0,0 & 2 & 11 & 349,9 & 351,9 & 99 & 0 & 18 \\
\hline RM & 6,7 & 5,6 & 45 & 10,8 & 236 & 72 & 0,0 & 2 & 11 & 329,8 & 331,8 & 99 & 0 & 13 \\
\hline $\mathrm{VN}$ & 6,6 & 5,7 & 6 & 5,6 & 174 & 87 & 0,0 & 2 & 6 & 272,6 & 279,6 & 97 & 0 & 16 \\
\hline \multicolumn{15}{|c|}{$10-20$} \\
\hline $\mathrm{CT}$ & 7,2 & 6,1 & 32 & 14,9 & 242 & 84 & 0,0 & 2 & 12 & 352,9 & 354,9 & 99 & 0 & 11 \\
\hline RM & 7 & 6,0 & 45 & 8,6 & 209 & 73 & 0,0 & 2 & 15 & 305,6 & 307,6 & 99 & 0 & 8 \\
\hline VN & 6,8 & 5,4 & 4 & 3,8 & 165 & 78 & 0,0 & 11 & 10 & 256,8 & 267,8 & 96 & 0 & 11 \\
\hline
\end{tabular}

Para a coleta da macrofauna do solo utilizouse o método do TSBF (Tropical Soil Biology and Fertility) (Anderson e Ingram, 1993). As densidades de indivíduos das ordens identificadas foram submetidas à medição dos índices de diversidade de Shannon (H) e Equitabilidade (J), utilizando o programa PAST versão 3.0. Os índices foram trabalhados tanto de forma geral para cada área, quanto em cada profundidade, para cada uma das três áreas.

\subsection{Caracterização de atributos físicos do solo}

$\mathrm{Na}$ análise granulométrica das amostras foi verificada a distribuição de diâmetro de partículas primárias, de acordo com o método de Densímetro (Hidrômetro de Bouyoucos) (Embrapa, 2011). Enquanto para os parâmetros densidade, microporosidade, macroporosidade e porosidade total do solo, em laboratório, as amostras foram saturadas com água destilada por um período de 48 horas e colocadas sob tensão de -6 kPa em mesa de tensão. Ao se estabilizar o peso na mesa, as amostras foram secas em estufa a $105^{\circ} \mathrm{C}$, até peso constante. Após obtenção dos pesos saturados, secos e depois do equilíbrio a $6 \mathrm{kPa}$, procedeu-se a determinação da densidade, microporosidade, macroporosidade e porosidade total do solo, baseado pela Embrapa (2011). Assim como, para cada condição foram determinados os principais pontos da curva de retenção de água definidos como capacidade de campo do solo (33 KPa) e ponto de murcha permanente $(1500 \mathrm{KPa})$ e com isso foi determinado à disponibilidade total de água no solo (Embrapa, 2011).

\section{Resultados e Discussão}

\subsection{Atributos Biológicos}

As avaliações de diversidade microbiana, realizadas através das UFC, mostraram maiores para os fungos em todas as áreas e profundidades (Tabela 2).

Tabela 2 Contagens de unidades formadoras de colônias em Vertissolo Cromado sob diferentes condições de usos e profundidades

\begin{tabular}{|c|c|c|c|c|}
\hline \multirow{3}{*}{ Áreas } & \multicolumn{3}{|c|}{ Bactérias } & \multirow[t]{2}{*}{ ungos } \\
\hline & \multicolumn{3}{|c|}{ Profundidade $(\mathrm{cm})$} & \\
\hline & $0-10$ & $10-20$ & $0-10$ & $10-20$ \\
\hline & \multicolumn{4}{|c|}{ - } \\
\hline Capim tifton & $4,20 \times 10^{4}$ & $9,90 \times 10^{4}$ & $10,0 \times 10^{4}$ & $260 \times 10^{4}$ \\
\hline Romã & $5,80 \times 10^{4}$ & $4,10 \times 10^{4}$ & $140 \times 10^{4}$ & $4,50 \times 10^{4}$ \\
\hline Vegetação nativa & $1,30 \times 10^{4}$ & $4,50 \times 10^{4}$ & $39,0 \times 10^{4}$ & $290 \times 10^{4}$ \\
\hline
\end{tabular}

UFC: Unidades Formadoras de Colônias 
Entre esses diferentes usos e profundidades estudados, a área de capim tifton foi a que apresentou maior número de UFC bacterianas, com média de $9,90 \times 10^{4} \mathrm{UFC}^{-1}$ na camada subsuperficial. Para os fungos, estes foram mais representativos na área sob vegetação nativa, o que elevou a densidade total, tornando a área que se apresentou com maior quantidade geral de

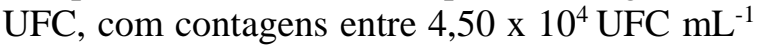
para bactérias e $290 \times 10^{4} \mathrm{UFC} \mathrm{mL}^{-1}$ para fungos (Tabela 2), destacando na camada subsuperficial. Implicando que em vegetação nativa há maior quantidade de fungos e bactérias o que evidencia maior equilíbrio biológico. Souto et al. (2008) ao avaliarem as comunidades microbianas de solo na Caatinga também obtiveram maiores populações de fungos, especialmente nos períodos mais secos. Em contraste, Lima et al. (2014), ao estudarem solo sob Caatinga arbórea (natural) de unidade de conservação, obtiveram valores médios maiores para bactérias totais e menores para fungos filamentosos.

As profundidades mostraram maiores densidades gerais na camada subsuperficial, tanto para bactérias quanto para fungos. Considerando os diferentes usos do solo individualmente, apenas a área sob cultivo de romã não seguiu esse padrão, apresentando maiores concentrações na camada superficial, tanto para bactérias $(5,80 \mathrm{x}$ $\left.10^{4} \mathrm{UFC} \mathrm{mL}^{-1}\right)$ quanto para fungos $\left(140 \times 10^{4}\right.$ UFC $\mathrm{mL}^{-1}$ ); talvez, por se tratar de uma área recente de plantio em comparação as demais estudadas, assim apresentando uma formação radicular iniciante e pouco profunda.

Em relação aos grupos de fungos foram classificados 11 gêneros diferentes, sendo os grupos Acremonium, Aspergilus, Mucor e Cladosporium os que mais se destacaram (Figura 1).

O gênero Mucor teve grande abrangência, aparecendo em todas as áreas estudadas, ao menos em uma das duas profundidades analisadas. Este gênero possui ampla diversidade metabólica, fisiológica e morfológica (Moreira e Siqueira, 2006). Em relação aos diferentes usos, as áreas de capim tifton e vegetação nativa também tiveram predominância do gênero Mucor, enquanto a área de romã apresentou três gêneros em destaque, sendo estes Cladosporium, Aspergilus e Mucor. Fraga e Pereira (2012), atenta para o fato de o gênero Aspergilus ocorrer em grande quantidade de ambientes, pelo seu rápido crescimento e grande produção de estruturas reprodutoras.

Em relação às porcentagens de gêneros fúngicos identificados em Vertissolo Cromado sob diferentes condições de uso e profundidades, o gênero Mucor teve também predominância nas profundidades estudadas, considerando todos os usos do solo. Em todas as áreas, a camada mais profunda houve predominância do fungo Mucor. Já na camada superficial apesar deste gênero também se destacar, outros obtiveram considerável destaque, como Aspergilus e Acremonium em área sob vegetação nativa e Aspergilus e Cladosporium em área sob romã. Os três grupos de menor ocorrência (Paecilomyces, Lecanicillium e Gliocladium), só foram encontrados nas áreas de cultivo, não ocorrendo na área de sob vegetação nativa (Figura 1).

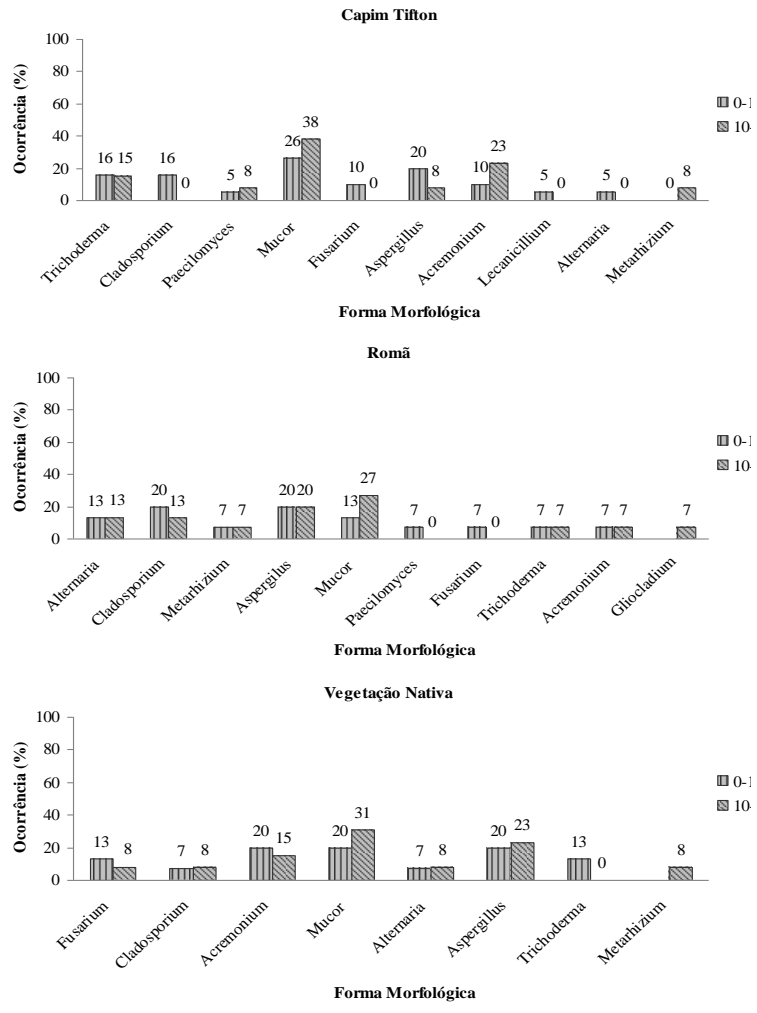

Figura 1 Porcentagens de gêneros fúngicos identificados em Vertissolo Cromado sob diferentes condições de uso e profundidades.

Porém, Martins (2015) obteve o gênero Lecanicillium em Caatinga preservada de Luvissolo e Neossolo, que demonstra que a ocorrência ou não deste gênero em área de sob vegetação nativa pode estar ligado a uma situação 
ocasional como o tipo de aporte do solo, bem como temperatura e ocorrência de umidade; pois, no estudo de Martins (2015) a ocorrência deste gênero mesmo presente nos dois solos em estudo - apresentou ocorrência distinta a exemplo do período seco e chuvoso, em que no período chuvoso houve aparecimento em amplos solos e condições de usos enquanto no período seco seu aparecimento se deu somente no solo Luvissolo em duas das três condições de usos estudadas.

Observando-se a Figura 2, os caracteres analisados para as bactérias mostraram predominância de gram negativas com pouca evidência de gram positivas.
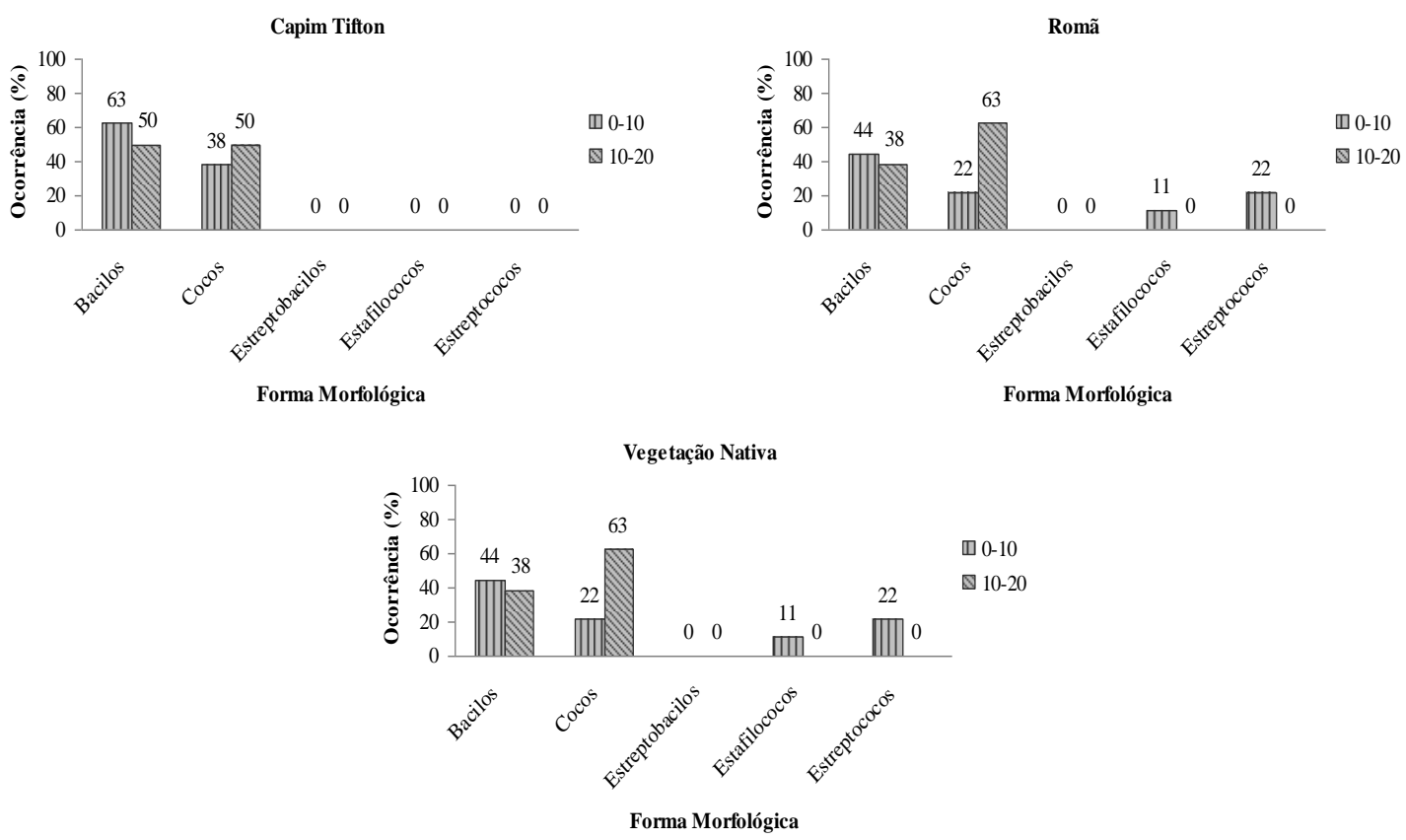

(A)

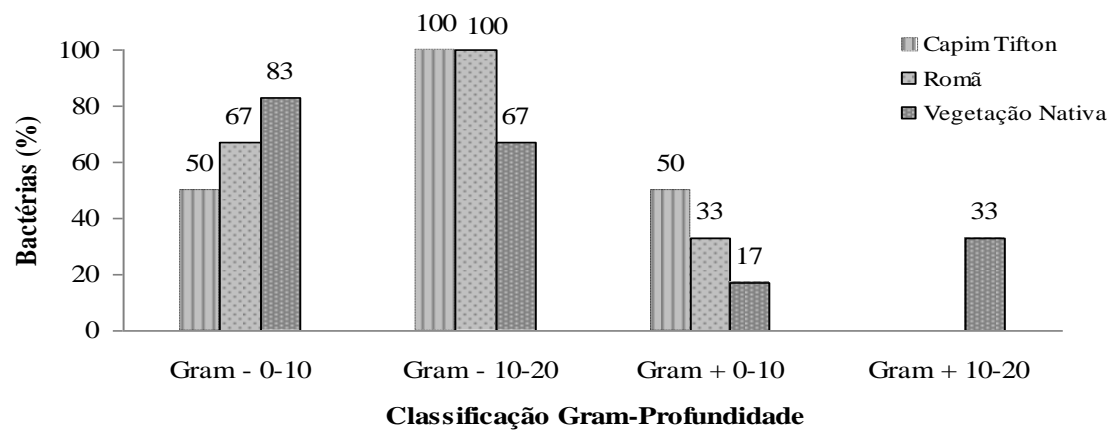

(B)

Figura 2 Porcentagens das densidades de bactérias quanto a formas morfológicas (a) e classificação de gram negativas (gram -) e positivas (gram +) (b), em diferentes condições de uso (CT - capim tifton, RM - romã e VN vegetação nativa) e profundidades de amostragem $(0-10$ e 10-20 cm).

Todavia, as bactérias gram positivas fizeram presentes em pelo menos uma das profundidades, com a área de capim tifton apresentando densidade levemente superior em comparação às demais áreas. $\mathrm{O}$ tipo morfológico mais predominante foram os bacilos, seguido de cocos. Menos expressivos, também ocorreram tipos variáveis de cocos e bacilos, sendo estes estafilococos, estreptococos e estreptobacilos. Martins (2015) também observou predomínio de gram negativas e formas de bastonetes e cocos enfatizando que tais bactérias são as representantes de maior abundância e diversidade entre os microrganismos do solo. Em relação às 
profundidades, a camada superficial apresentou maior concentração de bacilos, ficando a camada subsuperficial com representatividade uniforme entre as duas formas morfológicas. As variações de cocos e bacilos apenas ocorreram nas camadas superficiais. A área sob vegetação nativa foi a única a apresentar Gram positivas nas duas camadas.

Vale salientar que no presente trabalho o uso de meio não específico para o crescimento dos microrganismos analisados impede conclusões mais aprofundadas sobre a predominância das populações, o que vem corroborar com Martins (2015), além deste método proporcionar apenas uma análise inicial da diversidade microbiana, fazendo-se necessários estudos mais aprofundados sobre a diversidade genética, através de análises moleculares na área do estudo.

A atividade microbiana do solo, medida pela respiração basal, mostrou-se mais elevada na área sob cultivo de capim tifton em ambas as profundidades (Tabela 3 ).

Tabela 3 Atividade microbiana, medida pela respiração basal, de Vertissolo Cromado sob diferentes condições de uso e profundidades

\begin{tabular}{ccc}
\hline Áreas & Profundidades (cm) \\
& $0-10$ & $10-20$ \\
\hline & $------\mathrm{mg} \mathrm{C}^{-} \mathrm{CO}_{2} \mathrm{~kg}^{-1}$ & solo ------ \\
Capim tifton & 243 & 189 \\
Romã & 227 & 123 \\
Vegetação nativa & 118 & 90 \\
\hline
\end{tabular}

$\mathrm{Na}$ área sob cultivo de capim tifton em ambas as profundidades, a atividade microbiana do solo, foi mais elevada, possivelmente por está relacionado às maiores taxas de matéria orgânica (Tabela 1). Carvalho et al. (2008) observaram crescente respiração do solo ao incremento de material orgânico de serapilheira. Além disso, esta gramínea possui sistema radicular bastante abrangente, que aumenta a área rizosférica do solo sob esse cultivo. Essa cultura também apresenta a característica de ser perene, tendo seu efeito no aumento de fitomassa do solo. Por tanto, esses fatores podem ter contribuído para melhores condições de desenvolvimento para os microrganismos, e consequentemente aumentando sua atividade na referida cultura.

Em relação às profundidades, a camada superficial apresentou maior taxa de respiração, nas três áreas em estudo. Silva et al. (2010) também obtiveram maiores valores de respiração basal na camada superficial, na grande maioria dos sistemas de manejo do solo avaliados.

A área sob vegetação nativa foi a que apresentou menores taxas de atividade respiratória. Isso pode estar relacionado ao tipo de manejo empregado nas áreas cultivadas, que emprega técnicas conservacionistas, como o não revolvimento do solo e adubação orgânica, influenciando no maior aporte de matéria orgânica, levando a um maior incremento de $\mathrm{C}$ (Carbono), contribuindo para aumento na atividade microbiana, de tal modo que superou os incrementos naturais ocorridos na área de vegetação nativa (Tabela 2 ).

Lisboa et al. (2012) ao avaliarem a qualidade do solo em diferentes sistemas de manejo, a comparação entre campo nativo $(\mathrm{CN})$ e sistema com plantio direto (PD) não obteve diferença significativa na atividade respiratória dos microrganismos. Os mesmos autores concluíram que, em termos de respiração microbiana, existiu equivalência entre estes sistemas no referido estudo. Já Lourente et al. (2011), obtiveram valores de respiração basal maiores em área sob vegetação nativa, comparada aos diferentes sistemas de manejo.

Em relação à macrofauna, no total, foram coletados 132 indivíduos, das três áreas e duas profundidades consideradas. Formas jovens e materiais não identificados somaram 42 , das quais três foram larvas de coleóptera na área de romã, incluindo as duas profundidades, três materiais não identificados e 36 pupas abertas e imaturas, na área com vegetação nativa, considerando as duas profundidades (Figura 3).

A macrofauna coletada nas três áreas mostrouse em maior destaque, em termos de quantidade de indivíduos, na área com cultivo de capim tifton. Esta apresentou 52,3\% de todos os indivíduos coletados nas três áreas e duas profundidades estudadas, sendo a ordem Hymenoptera com maior densidade de indivíduos, se destacando entre as cinco ordens identificadas na área (Figura 4).

A riqueza total de grupos foi de onze ordens identificadas. A quantidade da macrofauna edáfica nos três diferentes usos seguiu a seguinte hierarquia: capim tifton > romã > vegetação nativa, onde a porcentagem geral de cada ordem, 
englobando esses três usos e as duas profundidades.

O solo da área de romã obteve $33,3 \%$ do total de indivíduos, tendo como Oligochaeta a ordem de destaque. Esta área obteve sete ordens diferentes identificadas. A área de vegetação nativa obteve apenas $14,4 \%$ do total de indivíduos coletados, tendo a ordem Isoptera em destaque, das 9 ordens identificadas.

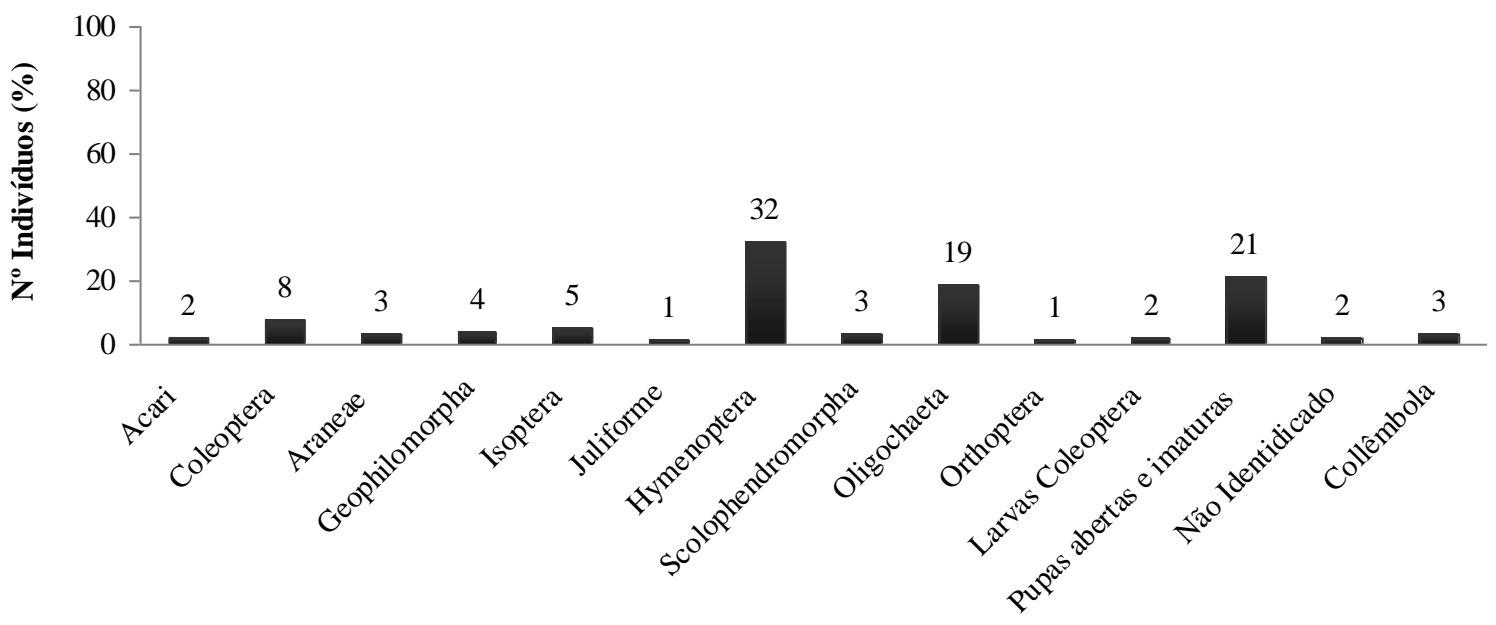

Ordem

Figura 3 Quantificação e classificação da macrofauna de Vertissolo Cromado sob diferentes condições de uso em única profundidade $(0-20 \mathrm{~cm})$.
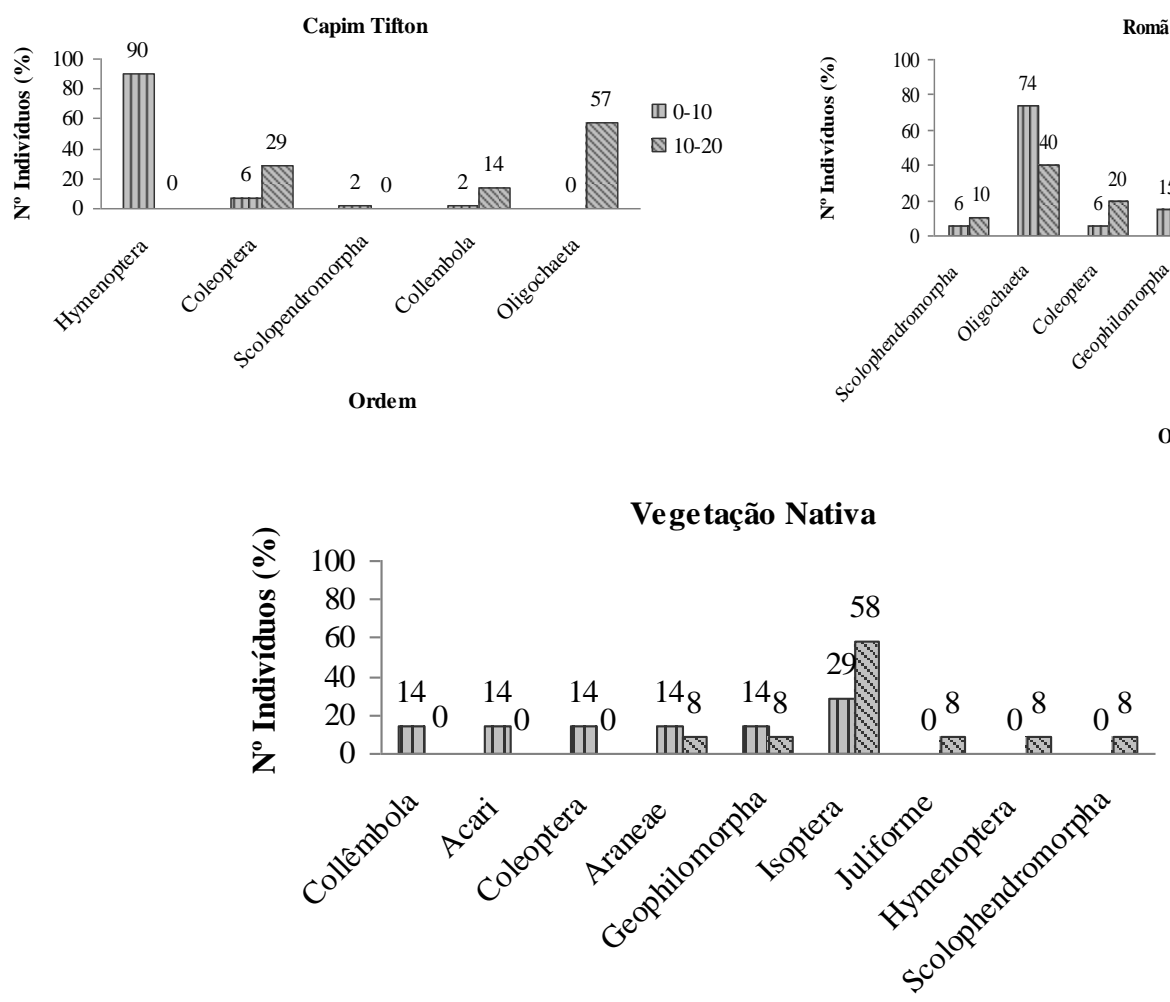

\section{Ordem}

Figura 4 Quantificação das ordens identificadas nas áreas sob diferentes condições de uso: a) capim tifton; b) romã; c) vegetação nativa, sob profundidades de amostragem. 
As ordens mais expressivas nas três áreas se assemelharam a diversos estudos de fauna edáfica, que obtiveram algumas destas ordens entre as que se mostraram em evidência (Lima et al., 2007; Montenegro, 2012; Pimentel et al., 2012). A ordem de destaque na área sob vegetação nativa, se assemelhou ao estudo de Batista et al. (2014), onde o grupo Isoptera foi expressivo na área de Cerradão, ficando pouco evidenciada nas áreas com produtividade.

A ordem Hymenoptera não só se destacou na área com capim tifton, mas foi à ordem que mais apresentou densidade de indivíduos no presente estudo. Este resultado se assemelhou ao de Pimentel et al. (2012) que obteve esta ordem em maior abrangência sob cultura de melão (Cucumis melo L.) previamente tratada com plantas de cobertura em mistura de culturas.

Quanto à profundidade, as áreas de capim tifton e romã apresentaram maior quantidade de indivíduos na profundidade mais superficial. Os maiores teores de matéria orgânica nesta camada (Tabela 1) pode ter contribuído para esta maior densidade na fauna edáfica. A área de vegetação nativa foi a única a apresentar maior representatividade de organismos na camada subsuperficial.
Os resultados das áreas de capim tifiton e romã se assemelharam ao estudo de Lima et al. (2007) que obtiveram em torno de $80 \%$ da fauna edáfica estudada, em diferentes consórcios sob cultivo orgânico, na camada superficial. A área de vegetação nativa obteve maior densidade total na camada mais profunda pode ser explicada, por esta área não receber incrementos de forma regular na camada superficial, como é feita nas áreas com produção orgânica, ficando toda biota desta, completamente condicionada aos efeitos naturais do ambiente, como por exemplo, efeitos sazonais da temperatura e pluviosidade. Este fato pode ser de certo modo, sustentado pela área de capim tifton, que obteve o maior teor de matéria orgânica (Tabela 1), fato que pode ter proporcionado melhores condições de nutrientes para a macrofauna, sendo ainda a que apresentou maior número total de indivíduos classificados.

Os índices de diversidade dos grupos identificados nas áreas estudadas, obtidos através do índice de Shannon (H) e de Equitabilidade (J), revelaram menor diversidade nas áreas que obtiveram maiores densidades de organismos (Tabela 4).

Tabela 4 Índices de diversidade de Shannon (H) e de Equitabilidade (J) para diferentes condições de uso e profundidades $(\mathrm{cm})$ em Vertissolo Cromado

\begin{tabular}{|c|c|c|c|c|c|c|}
\hline \multirow{3}{*}{ Áreas } & \multicolumn{2}{|c|}{ Índice Geral (0-20) } & \multicolumn{4}{|c|}{ Índice por profundidade } \\
\hline & \multirow{2}{*}{ Shannon $(\mathrm{H})$} & \multirow{2}{*}{ Equitabilidade (J) } & \multicolumn{2}{|c|}{$0-10$} & \multicolumn{2}{|c|}{$10-20$} \\
\hline & & & Shannon $(\mathrm{H})$ & Equitabilidade $(\mathrm{J})$ & Shannon $(\mathrm{H})$ & Equitabilidade (J) \\
\hline Romã & 1,181 & 0,607 & 0,841 & 0,607 & 1,609 & 0,898 \\
\hline Capim Tifton & 0,711 & 0,442 & 0,402 & 0,289 & 0,956 & 0,869 \\
\hline Vegetação nativa & 1,758 & 0,800 & 1,748 & 0,976 & 1,350 & 0,753 \\
\hline
\end{tabular}

Portanto, a área sob cultivo de capim tifton foi a que apresentou os menores índices de diversidade. Quanto maior for o valor do $\mathrm{H}$, maior poderá ser a diversidade neste ecossistema (Montenegro, 2012). O H se relaciona com a riqueza de um ecossistema, enquanto o $\mathrm{J}$ mede a regularidade em que os indivíduos podem estar distribuídos nos grupos.

O J contribuiu para validar o fato de que o menor valor de $\mathrm{H}$ na área de capim tifton pode estar associado a grande dominância de uma única ordem, Hymenoptera, o que elevou bastante sua densidade total de indivíduos, diminuindo os índices de diversidade para esta área. Pimentel et al. (2012) também obtiveram índices de diversidade inversamente proporcional à densidade, onde altas densidades também foram associadas a formigas, principalmente. Percebese então, que no tipo de uso que sofre menos alterações foi a que se apresentou com maior diversidade, embora a densidade de indivíduos tenha sido baixa.

Este padrão foi seguido quanto às profundidades de cada área, ocorrendo o mesmo principalmente na área de capim tifton, na camada superficial, uma vez que a ordem 
Atributos físicos e biológicos em Vertissolo Cromado sob agricultura biodinâmica na ... Costa et al.

dominante em questão se concentrou nesta camada.

\subsection{Atributos Físicos}

Tabela 5 Análise granulométrica e classificação textural de Vertissolo Cromado sob diferentes condições de uso e profundidades de amostragem

\begin{tabular}{|c|c|c|c|c|c|}
\hline \multirow{2}{*}{ Uso } & \multirow{2}{*}{ Profundidade } & \multicolumn{3}{|c|}{ Classe Textural } & \multirow{2}{*}{ Classificação Textural } \\
\hline & & Areia & Silte & Argila & \\
\hline & $-\mathrm{cm}-$ & \multicolumn{3}{|c|}{-------- g kg $^{-1}$} & \\
\hline Romã & & 274 & 380 & 346 & Franco Argilosa \\
\hline Capim Tifton & $0-10$ & 232 & 343 & 425 & Argila \\
\hline Vegetação nativa & & 258 & 460 & 282 & Franco \\
\hline Média & & 260 & 386 & 354 & \\
\hline Romã & & 356 & 365 & 279 & Franco \\
\hline Capim Tifton & $10-20$ & 336 & 354 & 310 & Franco Argiloso \\
\hline Vegetação nativa & & 272 & 451 & 277 & Franco \\
\hline Média & & 322 & 394 & 284 & \\
\hline
\end{tabular}

A camada superficial apresentou-se com maior quantidade de silte na área sob vegetação nativa, seguido da área com cultivo de romã. A área de capim tifton, nesta camada, apresentou maior teor de argila. Na camada subsuperficial, a mesma tendência foi observada, com exceção da área de capim tifton, que nesta camada apresentou maior teor de silte. $\mathrm{O}$ teor de areia foi inferior em todas as áreas e profundidades de amostragem, exceto na camada subsupeficial para as áreas de romã e capim tifton.

As condições granulométricas variaram em função dos diferentes manejos, ficando a
As análises físicas mostram maiores quantidades de silte, independente dos usos e profundidades estudadas (Tabela 5).

Tabela 6 Densidade do solo (DS), macro e microporosidade e porosidade total de Vertissolo Cromado em diferentes condições de uso e profundidades

\begin{tabular}{|c|c|c|c|c|c|}
\hline \multirow{2}{*}{ Uso } & \multirow{2}{*}{ Profundidade } & \multirow{2}{*}{ DS } & \multicolumn{3}{|c|}{ Porosidade } \\
\hline & & & Macro & Micro & Total \\
\hline & $\mathrm{cm}$ & $-\mathrm{g} \mathrm{dm}^{-3}-$ & \multicolumn{3}{|c|}{------------ $\mathrm{m}^{3} \mathrm{~m}^{-3}$----------- } \\
\hline Romã & & 1,16 & 0,09 & 0,49 & 0,58 \\
\hline Capim Tifton & $0-10$ & 1,08 & 0,10 & 0,51 & 0,60 \\
\hline Vegetação nativa & & 1,11 & 0,21 & 0,39 & 0,60 \\
\hline Média & & 1,12 & 0,13 & 0,46 & 0,59 \\
\hline Romã & & 1,22 & 0,18 & 0,43 & 0,61 \\
\hline Capim Tifton & $10-20$ & 1,22 & 0,10 & 0,48 & 0,58 \\
\hline Vegetação nativa & & 1,30 & 0,16 & 0,39 & 0,56 \\
\hline Média & & 1,25 & 0,15 & 0,43 & 0,58 \\
\hline
\end{tabular}

Em relação à densidade, os maiores valores absolutos mostraram que a camada subsuperficial obteve maior densidade. Entre as condições de uso, foram verificados maiores valores na área com romã, seguida de vegetação nativa e menores classificação textural entre Franco Argilosa e Argila. Isso reflete no espaço poroso e retenção de água.

Sendo assim, a textura é considerada um dos principais indicadores da qualidade e produtividade dos solos, ao afetar importantes processos edáficos, como a dinâmica de água no solo (Klein, 2008).

Quanto aos atributos de densidade, macro e microporosidade, e porosidade total, estes estão apresentados na Tabela 6. 
capim tifton obtiveram os maiores valores na camada superficial, onde os teores de matéria orgânica foram maiores (Tabela 1).

A maior proporção de porosidade total pode ter favorecido a atividade microbiana, onde a maior média na camada superficial pode estar relacionada às maiores taxas de respiração nesta camada, sendo também o que obteve as maiores taxas de respiração entre os usos (Tabela 4).

Com a predominância das frações de silte e argila, principalmente na camada superficial, pode-se observar maior microporosidade, onde em termos médios, os valores variaram entre 0,46 e $0,43 \mathrm{~m}^{3} \mathrm{~m}^{-3}$ entre as camadas de 0-10 e 10-20 $\mathrm{cm}$, respectivamente. Em relação a macroporosidade, onde em termos médios, os valores oscilaram de 0,13 a $0,15 \mathrm{~m}^{3} \mathrm{~m}^{-3}$ entre as camadas de 0-10 e 10-20 cm, respectivamente.

Esta dominância de microporos, na camada superficial, pode ter contribuído para menores contagens de diversidade microbiana na referida camada, uma vez que a redução da porosidade de aeração, a macroporosidade, pode acarretar em menor disponibilidade de oxigênio disponível, por exemplo, se constituindo em uma barreira física (Moreira e Siqueira, 2006) ao melhor desenvolvimento de certos microrganismos, o que pode ter contribuído em algum grau para essa variação.

A porosidade de um determinado solo influencia na aeração, condução e retenção de água, resistência à penetração e ramificação das raízes no solo e, como consequência, na disponibilidade de água e nutrientes (Tognon, 1991). A composição de um solo ideal, em relação aos poros, é que estes tenham volume e dimensão adequada para entrada, movimento e retenção de água e ar que atendam as necessidades da cultura (Hillel, 1998).

Sendo assim, a capacidade de campo na camada 0-10 $\mathrm{cm}$ foi maior nas áreas de capim tifton e romã. Na camada de $10-20 \mathrm{~cm}$ o mesmo padrão foi seguido para área de capim tifton, enquanto que a área de romã apresentou o menor valor nesta camada (Tabela 7).

Tabela 7 Capacidade de campo (CC), ponto de murcha permanente (PMP) e água disponível (AD) em Vertissolo sob diferentes condições de uso e profundidades

\begin{tabular}{ccccc}
\hline Uso & Profundidade & CC & PMP & AD \\
\hline & $\mathrm{cm}$ & 0,166 & 0,161 & 0,005 \\
Romã & & 0,160 & 0,157 & 0,004 \\
Capim Tifton & $0-10$ & 0,149 & 0,147 & 0,003 \\
Vegetação nativa & & 0,158 & 0,155 & 0,004 \\
\hline Média & & 0,166 & 0,163 & 0,003 \\
\hline Romã & 0,171 & 0,157 & 0,004 \\
Capim Tifton & \multirow{2}{*}{$10-20$} & 0,170 & 0,167 & 0,003 \\
Vegetação nativa & & 0,169 & 0,162 & 0,003 \\
\hline Média & &
\end{tabular}

Portanto, em termos médios a $\mathrm{CC}$ variou entre $0,158 \mathrm{~m}^{3} \mathrm{~m}^{-3}$ e 0,169 para as camadas $0-10$ e 10 $20 \mathrm{~cm}$, respectivamente. O PMP apresentou valores bem próximos aos da capacidade de campo, o que refletiu negativamente na disponibilidade de água no solo.

Com isso, pode-se observar maior disponibilidade de água no solo, na área cultivada com romã, na camada superficial, e na de capim tifton na subsuperficial. A área sob vegetação nativa apresentou menor disponibilidade de água em ambas as profundidades. Porém, independente das condições de uso e profundidades estudadas, percebe-se baixa disponibilidade de água para as plantas.
O leve aumento na capacidade de retenção de água na camada superficial na área de romã pode ter contribuído para maior contagem de diversidade microbiana nesta área na referida camada, uma vez que as outras duas áreas apresentaram maior contagem na camada mais profunda (Tabela 2). Portanto, maior disponibilidade de água pode refletir em melhores condições para os microrganismos. Para Moreira e Siqueira (2006), pode-se considerar que todos os microrganismos do solo são totalmente dependentes de água para absorção de nutrientes e integridade celular.

\section{Conclusão}


A diversidade microbiana apresentou-se, de modo geral, com maior densidade na área sob vegetação nativa;

A atividade microbiana foi mais ativa nas camadas superficiais em todas as condições de uso e profundidades;

A densidade de macrofauna mostrou-se maior na área de cultivo de capim tifton, porém obteve os valores mais baixos nos índices de diversidade e equitabilidade, ficando para a área sob vegetação nativa os maiores valores destes índices, sugerindo nesta área uma maior diversidade.

A diversidade microbiana foi mais expressiva na camada de $10-20 \mathrm{~cm}$ podendo ter relação com menores valores de microporosidade nesta camada.

Os atributos físicos obtiveram maiores valores de porosidade total e conteúdo de matéria orgânica podem ter contribuído em maior atividade microbiana na área sob capim tifton e a maior densidade de macrofauna nesta área.

\section{Referências}

Abdulkadir, M.; Waliyu, S. Screening and Isolation of the Soil Bacteria for Ability to Produce Antibiotics. European Journal of Applied Sciences, v.4, n.5, p.211-215, 2012. http://doi:10.5829/idosi.ejas.2012.4.5.2011

Anderson, J.; Ingram, J. Soil fauna. In: Tropical soil biological and fertility: a handbook of methods. $2^{\mathrm{a}}$ ed. Wallingford: C.A.B. International, 1993. p. 44-46.

Batista, I.; Correia, M. E. F.; Pereira, M. G.; Bieluczyk, W.; Schiavo, J. A.; Rouws, J. R. C. Frações oxidáveis do carbono orgânico total e macrofauna edáfica em sistema de integração lavoura-pecuária. Revista Brasileira de Ciência do Solo, v.38, n.3, p.797-809, 2014. http://dx.doi.org/10.1590/S0100-06832014000300011

Carvalho, A. M. X.; Vale, H. M. M. do; Ferreira, E. M.; Cordero, A. F. P.; Barros, N. F. de; Costa, M. D. Atividade microbiana de solo e serapilheira em áreas povoadas com Pinus elliottii e Terminali aivorensis. Revista Brasileira de Ciência do Solo, v.32, número especial, p.2709-2716, 2008. http://dx.doi.org/10.1590/S0100-06832008000700014
Embrapa. Sistema Brasileiro de Classificação de Solos. 4a ed. Brasília: Embrapa Solos 2014. $376 \mathrm{p}$.

Embrapa. Manual de métodos de análise de solo. $2^{\text {a }}$ ed. Rio de Janeiro: Embrapa Solos, 2011. $230 \mathrm{p}$

Fraga, M.; Pereira, M. Diversidade de Trichocomaceae isolada de solo e serrapilheira de Floresta Atlântica. Floresta e Ambiente, v.19, n.4, p.405-413, 2012. http://dx.doi.org/10.4322/floram.2012.045

Hillel, D. Environmental soil physics. Academic Press: New York. 1998, 771p.

Klein, V. Física do solo. Passo Fundo: Universidade de Passo Fundo, 2008. 212 p.

Lima, J. V. L.; Pinheiro, M. de S.; Fiúza, L. M. C. G.; Martins, S. C. S.; Martins, C. M. Populações microbianas cultiváveis do solo e serrapilheira de uma unidade de conservação no semiárido brasileiro. Enciclopédia Biosfera, v.10, n.18, p.2300, 2014. http://conhecer.org.br/enciclop/2014a/AGRARIAS/popul acoes.pdf

Lima, H. V; Oliveira, T. S. de; Oliveira, M. M. de; Mendonça, E. de S.; Lima, P. J. B. F. Indicadores de qualidade do solo em sistemas de cultivo orgânico e convencional no semi-árido cearense. Revista Brasileira de Ciência do Solo, v.31, n.5, p.1085-1098, 2007. http://dx.doi.org/10.1590/S0100-06832007000500024

Lisboa, B. B.; Vargas, L. K.; Silveira, A. O. da; Martins, A. F.; Selbach, P. A. Indicadores microbianos de qualidade do solo em diferentes sistemas de manejo. Revista Brasileira de Ciência do Solo, v. 36, n. 1, p. 45-55, 2012. http://dx.doi.org/10.1590/S0100-06832012000100004

Lourente, E. R. P.; Mercante, F. M.; Alovisi, A. M. T.; Gomes, C. F.; Gasparini, A. D.; Nunes, C. M. Atributos microbiológicos, químicos e físicos de solo sob diferentes sistemas de manejo e condições de Cerrado. Pesquisa Agropecuária Tropical, v.41, n.1, p.20-28, 2011 http://.dx.doi.org/10.5216/pat.v41i1.8459

Martins, A. F. Inter-relações entre atributos do solo sob diferentes coberturas vegetais no Núcleo de Desertificação do Seridó. Areia, 94 p. Tese (Doutorado em Ciência do solo), Centro de Ciências Agrárias, Universidade Federal da Paraíba, 2015. 
Montenegro, F. Identificação da macrofauna edáfica na cultura da mamoneira (Ricinus communis L.) no munícipio de Lagoa SecaPB. Lagoa Seca, 18 p. Monografia (Graduação em Agroecologia) Universidade Estadual da Paraíba, 2012.

Moreira, F.; Siqueira, J. Microbiologia e bioquímica do solo. 2 . ed. Lavras: Universidade Federal de Lavras, 2006. 729 p.

Pimentel, M. S.; Carvalho, R. S.; Vilaronga, D. P.; Martins, L. M. V.; Silva, A. V. L. da. Dynamico of fepigeous macrofauna under organic soil management in the Brazilian semiarid region. Semina: Ciências Agrárias, v.33, n.1, p.183-192, 2012. http://dx.doi.org/10.5433/1679$\underline{0359.2012 \mathrm{v} 33 \mathrm{n} 1 \mathrm{p} 183}$

Rieff, G. Monitoramento de ácaros e colêmbolos como potenciais indicadores biológicos de qualidade do solo. Porto Alegre, 59 p. Dissertação (Mestrado em Ciência do Solo) Faculdade de Agronomia, Universidade Federal do Rio Grande do Sul, 2010.

Santos, E. A. Variabilidade no regime pluvial nasmicrorregiões do sertão da Paraíba nos anos de El Niño oscilação sul. Campina Grande, 98 f. Monografia (Graduação em
Licenciatura Plena em Geografia) Universidade Estadual da Paraíba, 2012.

Silva, R. R.; Silva, M. L. N.; Cardoso, E. L.; Moreira, F. M. de S.; Curi, N.; Alovisi, A. M. T. Biomassa e atividade microbiana em solo sob diferentes sistemas de manejo na região fisiográfica Campos das Vertentes-MG. Revista Brasileira de Ciência do Solo, v.34, p.1585-1592, 2010. http://scielo.br/pdf/rbcs/v34n5/11.pdf

Souto, P. C.; Souto, J. S.; Miranda, J. R. P de; Santos, R. V. dos; Alves, A. R. Comunidade microbiana e mesofauna edáficas em solo sob Caatinga no semi-árido da Paraíba. Revista Brasileira de Ciência do Solo, v.32, n.32, p.151-160, 2008. http://dx.doi.org/10.1590/S0100$\underline{06832008000100015}$

Tognon, A. Propriedades físico-hídricas do Latossolo Roxo da região de Guairá-SP sob diferentes sistemas de cultivo. Piracicaba, 85 p. Dissertação (Mestrado) Escola Superior de Agricultura Luiz de Queiroz, 1991.

Vance, E. D.; Brookes, P. C.; JenkinSon, D. S. An extraction method for measuring soil microbial biomass C. Soil Biology and Biochemistry, v.19, n.6, p.703-707, 1987. http://doi.org/10.1016/0038-0717(87)90052-6 